Article

\title{
Interaction between Shiga Toxin and Monoclonal Antibodies: Binding Characteristics and in Vitro Neutralizing Abilities
}

\author{
Letícia B. Rocha ${ }^{1}$, Daniela E. Luz ${ }^{1}$, Claudia T. P. Moraes ${ }^{1}$, Andressa Caravelli ${ }^{1}$, \\ Irene Fernandes ${ }^{2}$, Beatriz E. C. Guth ${ }^{3}$, Denise S. P. Q. Horton ${ }^{1}$ and Roxane M. F. Piazza ${ }^{1, *}$
}

1 Bacteriology Laboratory, Butantan Institute, São Paulo, SP, Brazil;

E-Mails: leticiarocha@butantan.gov.br(L.B.R.); daniedaluz@butantan.gov.br (D.E.L.); claudiatrigo@butantan.gov.br (C.T.P.M.); andressacaravelli@butantan.gov.br (A.C.); dhorton@butantan.gov.br (D.S.P.Q.H.)

2 Immunopathology Laboratory, Butantan Institute, São Paulo, SP, Brazil;

E-Mail: irenefernandes@butantan.gov.br

3 Departament of Microbiology, Immunology, Parasitology, Escola Paulista de Medicina, Federal University of São Paulo, São Paulo, SP, Brazil; E-Mail: bec.guth@unifesp.br

* Author to whom correspondence should be addressed; E-Mail: roxane@butantan.gov.br.

Received: 28 August 2012; in revised form: 17 September 2012 / Accepted: 17 September 2012 / Published: 18 September 2012

\begin{abstract}
Monoclonal antibodies (MAbs) have been employed either for diagnosis or treatment of infections caused by different pathogens. Specifically for Shiga toxin-producing Escherichia coli (STEC), numerous immunoassays have been developed for STEC diagnosis, showing variability in sensitivity and specificity when evaluated by reference laboratories, and no therapy or vaccines are currently approved. Thus, the aim of this work was the characterization of the interaction between MAbs against Stx1 and Stx2 toxins and their neutralizing abilities to enable their use as tools for diagnosis and therapy. The selected clones designated 3E2 (anti-Stx1) and 2E11 (anti-Stx2) were classified as IgG1. 3E2 recognized the B subunit of Stx1 with an affinity constant of $2.5 \times 10^{-10} \mathrm{M}$, detected as little as $6.2 \mathrm{ng}$ of Stx 1 and was stable up to $50^{\circ} \mathrm{C}$. In contrast, 2E11 recognized the A subunit of Stx2, was stable up to $70{ }^{\circ} \mathrm{C}$, had a high dissociation constant of $6.1 \times 10^{-10} \mathrm{M}$, and detected as little as $12.5 \mathrm{ng}$ of Stx2. Neutralization tests showed that $160 \mathrm{ng}$ of $3 \mathrm{E} 2 \mathrm{MAb}$ inhibited $80 \%$ of Stx 1 activity and $500 \mu \mathrm{g}$ 2E11 MAb were required for $60 \%$ inhibition of Stx 2 activity. These MAb amounts reversed 25 to $80 \%$ of the cytotoxicity triggered by different STEC isolates. In conclusion, these MAbs show suitable
\end{abstract}


characteristics for their use in STEC diagnosis and encourage future studies to investigate their protective efficacy.

Keywords: Stx1; Stx2; monoclonal antibodies; binding; stability; detection; neutralizing ability; specificity

\section{Introduction}

Shiga toxin-producing Escherichia coli (STEC) strains and their subset, the enterohemorrhagic E. coli (EHEC) strains, contain a large pathogenicity island called the locus of enterocyte effacement and carry a 90-kb plasmid [1-3]. Not only the O157:H7 serotype, but also some other STEC serotypes have been associated mainly with food-linked outbreaks of Stx-mediated disease with the possibility of a complication such as the hemolytic uremic syndrome (HUS), which is characterized by hemolytic anemia, thrombocytopenia, and renal failure.

Shiga toxins (Stxs) are known to act systemically and therefore must cross from the site of STEC colonization in the gastrointestinal tract to the circulatory system [3]. There are two main subtypes of Stxs, Stx/Stx1 and Stx2. Stx and Stx 1 are practically identical, with only one amino acid difference in the A subunit. The A and B subunits of Stx1 and Stx2 differ at the amino acid level by 32 and 27\%, respectively, although their crystal structures show high similarity $[4,5]$.

Stxs have the $\mathrm{AB}_{5}$ structure, where the active domain $(\mathrm{A}-32 \mathrm{kDa})$ contains an $N$-glycosidase. This enzyme depurinates the $28 \mathrm{~S}$ rRNA of the $60 \mathrm{~S}$ ribosomal subunit and irreversibly inhibits protein synthesis, resulting in cell death. Subunit B consists of five identical 7.7-kDa monomers that form a pentamer, which allows the $\mathrm{C}$ terminus domain of the $\mathrm{A} 2$ peptide to traverse it. The $\mathrm{B}$ pentamer binds to the eukaryotic receptor globotriaosylceramide (Gb3Cer/CD77) or globotetraosylceramide (Gb4Cer) in the case of Stx2e [6-10], present on the plasma membrane of enterocytes and other cells, for example glomerular endothelial cells [10].

The Vero cell toxicity test detects functionally active toxin and is often used as the gold standard to evaluate diagnostic immunoassays $[11,12]$. Among the several commercially available immunoassays using monoclonal and/or polyclonal antibodies are VTEC-Screen (Seiken, Japan), Premier EHEC (Meridian Bioscience, US), Ridascreen Verotoxin (R-Biopharm, Germany), ProSpecT Shiga Toxin (Alexon-Trend, US), Immunocard STAT! EHEC (Meridian Diagnostics, US) and Duopath Verotoxins Gold Labeled Immunosorbent Assay (Merck, Germany). Some of them differentiate between Stx1 and Stx2 while others do not. The reported sensitivities and specificities of these immunoassays vary by test format and manufacturer. The standard by which each manufacturer evaluates its tests also varies; therefore, a direct comparison of performance characteristics of various immunoassays has not been performed [13].

Outbreaks of STEC infections can be contained by sanitary measures and by monitoring the water and food supply. Hence, immunization of the general population cannot be justified given the safety restrictions of a vaccine. Treatment of infected patients is needed to prevent progression of the infection to HUS [14]. However, despite remarkable advances in understanding STEC pathogenesis, the clinical options for treatment remain limited to mainly supportive strategies. The use of 
antimicrobials is controversial; mainly reflected by the effect of specific antimicrobial agents on phage induction and subsequent Stx gene expression and transcription [15], thereby allowing the undesirable release of verotoxin Stx, and thus being usually avoided [16-18].

There is no current approved treatment to combat or prevent illness from STEC, but several promising options for the future are under investigation. These options include several vaccine candidates such as Stx1 and Stx2 genetic toxoids, a plant-based Stx2 toxoid and a chimeric StxA2/StxB1 toxoid that elicits a neutralizing antibody response and provides protection against a lethal challenge of both Stx1 and Stx2 [19-21]. Passive immunization with monoclonal antibodies rose against Stx1 and Stx2 has been shown to be effective in animal models [22-30], and urtoxazumab, a humanized monoclonal antibody against Shiga-like toxin 2 is undergoing clinical trials [31].

Therefore, these compelling, important aspects of STEC infection relative to diagnosis and therapy motivated us to produce monoclonal antibodies against Stx 1 and Stx2. In the present study, we demonstrated their interactions and neutralization of Shiga toxins, and the results obtained support their use as tools in STEC diagnosis and encourage future studies to investigate their protective efficacy.

\section{Material and Methods}

\subsection{Toxins, Chemicals, Reagents, Antibodies and Supplies}

Purified Stx 1 and Stx2 were purchased from Tufts University School of Medicine, Boston, MA, USA. A Protein A affinity chromatography column was bought from GE Healthcare. Bovine serum albumin (BSA), polyethylene glycol 1500, goat anti-mouse IgG peroxidase-conjugated antibodies, goat anti-mouse IgG-FITC conjugated, o-phenylenediamine (OPD) and 3'3'-diaminobenzidine (DAB) were acquired from Sigma Aldrich (St Louis, MO, USA). Horseradish peroxidase-conjugated rabbit anti-mouse-IgG $+\mathrm{A}+\mathrm{M}$ purchased from Zymed (San Francisco, CA, USA). HAT-(10 mM hypoxanthine, $40 \mu \mathrm{M}$ aminopterin and $1.6 \mathrm{mM}$ thymidine) and fetal bovine serum (FBS) were acquired from GibcoBRL (Itapevi, SP, Brazil). Nitrocellulose membrane Hybond C-Extra was acquired from Amersham Biosciences (Little Chalfont, UK). For ELISA assays, we employed MaxiSorp microplates from Nunc (Rochester, NY, USA) and assay measurements were done in a Multiskan EX ELISA reader from Labsystems (Milford, MA, USA).

\subsection{Bacterial Isolates}

In this study, 45 STEC isolates from human and animal sources, belonging to different serotypes previously characterized by the presence of stx gene by polymerase chain reaction (PCR) [32-34] were used for MAbs characterization against Stx1 and Stx2. EDL933 was included in the assays as a positive control of the strain producing Stx1/Stx2. All strains were cultivated as described by Rocha and Piazza [33] to enhance expression of Stx by bacterial isolates and for Vero cell cytotoxicity assay $(\mathrm{VCA}) /$ neutralization assay. 


\subsection{Stx 1 and Stx2 Toxins and Toxoids}

Toxins were converted to toxoids by either formaldehyde or glutaraldehyde treatment using the protocol described by Donohue-Rolfe et al. [35] and Brown et al. [36], respectively, before immunization of the mice.

\subsection{Anti-Stx1 and Anti-Stx2 Monoclonal Antibody (MAb) Production}

Four to six week-old female BALB/c mice were immunized via the footpad with $10 \mu \mathrm{g}$ Stx1 or $3 \mu \mathrm{g}$ Stx2 toxoid adsorbed to $250 \mu \mathrm{g}$ aluminum hydroxide. The immunization protocols consisted of three booster injections of the toxoid $(10 \mu \mathrm{g})$ in $0.01 \mathrm{M}$ phosphate buffered saline, $\mathrm{pH} 7.4$ (PBS) at four-week intervals for Stx1 toxoid, and two booster injections (15 $\mu \mathrm{g})$ with a 15-day interval for Stx2 toxoid. The experiments were conducted in agreement with the Ethical Principles in Animal Research, adopted by the Brazilian College of Animal Experimentation, and they were approved by the Ethical Committee for Animal Research of Butantan Institute (469/08).

The mouse with the highest antibody titer was boosted with $10 \mu \mathrm{g}$ Stx 1 or $15 \mu \mathrm{g}$ Stx 2 toxoid three days prior to cell fusion. Serum samples were obtained just before the first immunization by the retro-orbital sinus method to be used as the negative control in specific antibody evaluation. Serum samples were also obtained ten days after the last antigen injection and subsequently analyzed by ELISA.

The popliteal lymphnode cells were fused with SP2/O-Ag14 mouse myeloma cells (2:1) using polyethylene glycol 1500 [37], with modifications. Hybrids were selected in RPMI 1640 medium plus $3 \%$ HAT containing $10 \% \mathrm{FBS}$ at $37{ }^{\circ} \mathrm{C}$ and $5 \% \mathrm{CO}_{2}$. The supernatant fluids were screened for species-specific antibodies by indirect ELISA.

For ELISA, hybridoma supernatant $(100 \mu \mathrm{L})$ was added to wells of a 96-well plate previously coated with $0.1 \mu \mathrm{g}$-purified toxins to screen cultures for antibody production. Antibody-secreting cells were expanded and cloned twice at limiting dilution. Hybridomas secreting MAbs were selected using STEC and other non-producing Stx isolates by capture ELISA.

\subsection{MAb Characterization}

\subsubsection{MAb Isotyping and Purification}

The microplate was coated overnight at $4{ }^{\circ} \mathrm{C}$ with $1 \mu \mathrm{g}$ goat anti-mouse IgG1, IgG2a, IgG2b, IgG3, $\operatorname{IgA}, \operatorname{IgM}$ and $\operatorname{IgE}$ in $0.05 \mathrm{M}$ sodium carbonate-bicarbonate buffer ( $\mathrm{pH}$ 9.6). Hybridoma supernatants were incubated with each of the isotype followed by incubation with horseradish peroxidase-conjugated rabbit anti-mouse-IgG+A+M (1:1,000). The supernatants from selected clones were filtered $(0.45 \mu \mathrm{m})$ and purified by protein A affinity chromatography. MAb purity was determined by $15 \%$ polyacrylamide gel electrophoresis containing sodium dodecyl sulfate (SDS-PAGE) [38,39] staining with Coomassie blue R-250. 


\subsubsection{Interaction of MAbs with Toxin: Definition of Detection Limit, Affinity and Stability}

Anti-Stx1 and Stx2 MAbs features were determined by ELISA. The detection limit was established using toxin concentrations from 100 to $0.09 \mathrm{ng}$ coated on microplates in a PBS solution at $4{ }^{\circ} \mathrm{C}$ for $16-18 \mathrm{~h}$. After blocking ( $1 \% \mathrm{BSA}$ at $37^{\circ} \mathrm{C}$ for $\left.30 \mathrm{~min}\right)$, toxins were incubated with $0.2 \mu \mathrm{g}$ anti-Stx 1 or anti-Stx 2 monoclonal antibody diluted in blocking buffer at $37^{\circ} \mathrm{C}$ for $1 \mathrm{~h}$, followed by incubation with goat anti-mouse peroxidase-conjugated antibody diluted 1:5,000, at $37{ }^{\circ} \mathrm{C}$ for $1 \mathrm{~h}$. The reaction was developed with $0.5 \mathrm{mg} / \mathrm{mL}$ OPD plus hydrogen peroxide $\left(\mathrm{H}_{2} \mathrm{O}_{2}\right)$, and stopped by the addition of $1 \mathrm{~N} \mathrm{HCl}$. The absorbance was measured at $492 \mathrm{~nm}$ in a Multiskan EX ELISA reader.

The cross reactivity between MAbs and toxins was determined by indirect ELISA using different anti-Stx 1 or anti-Stx $2 \mathrm{MAb}$ concentrations (ranged from $1.0 \mathrm{pg}$ to $10 \mu \mathrm{g}$ ) with a predetermined toxin concentration $(0.1 \mu \mathrm{g})$ as antigen.

Three-step ELISA described by Friguet et al. [40] was employed to determine the dissociation constants $\left(K_{D}\right)$ of antigen-antibody interactions under equilibrium conditions. Briefly, dilutions of different MAbs, selected in the linear part of the ELISA titration curves (determined by linear regression) were incubated overnight at $4{ }^{\circ} \mathrm{C}$ with various concentrations of antigen. The concentration of free MAb was determined by ELISA, where aliquots $(100 \mu \mathrm{L})$ of incubation medium were transferred to the wells of microtiter plates previously coated with Stx1 or Stx2. Dissociation constants were deduced from Scatchard plots.

The stability of anti-Stx1 and Stx2 MAbs was determined by indirect ELISA in which MAb solutions were kept at room temperature, or at $37{ }^{\circ} \mathrm{C}, 50{ }^{\circ} \mathrm{C}, 60{ }^{\circ} \mathrm{C}, 80^{\circ} \mathrm{C}, 90{ }^{\circ} \mathrm{C}$ and $100{ }^{\circ} \mathrm{C}$ for $10 \mathrm{~min}$. Tests were performed at different times up to $2 \mathrm{~h}$.

\subsubsection{Stx 1 and Stx 2 Characterization by Immunoblotting}

The reactivity of antibodies to purified Stx1 and Stx2 toxins was tested by immunoblotting using the monoclonal antibodies. Briefly, $10 \mu \mathrm{g}$ per slot of toxins were submitted to $15 \%$ SDS-PAGE. After electrophoresis, the separated proteins were transferred to a nitrocellulose membrane at $150 \mathrm{~mA}$ for $18 \mathrm{~h}$ at $4{ }^{\circ} \mathrm{C}$. The membrane was blocked with $1 \%$ BSA for $2 \mathrm{~h}$ and incubated with anti-Stx 1 or anti-Stx 2 monoclonal antibodies $(50 \mu \mathrm{g})$ at room temperature for $2 \mathrm{~h}$ and at $4{ }^{\circ} \mathrm{C}$ for $18 \mathrm{~h}$. Next, the membrane was washed and incubated at room temperature for $1 \mathrm{~h}$ with peroxidase-conjugated goat anti-mouse IgG (1:5,000). After washing, DAB plus $\mathrm{H}_{2} \mathrm{O}_{2}$ were added and the reaction was stopped after $15 \mathrm{~min}$ by the addition of distilled water.

\subsubsection{MAb Reactivity to Shiga Toxin-Producing E. coli}

MAb reactivity to the toxins expressed by STEC isolates was determined by capture ELISA using microplates coated with IgG-enriched fraction of anti-Stx $1(1 \mu \mathrm{g})$ or anti-Stx2 $(3 \mu \mathrm{g})$ from rabbit polyclonal serum $[35,36]$ at $4{ }^{\circ} \mathrm{C}$ for $16-18 \mathrm{~h}$. After blocking with $1 \%$ BSA at $37{ }^{\circ} \mathrm{C}$ for $30 \mathrm{~min}$, $100 \mu \mathrm{L}$ of isolates supernatants were incubated at $37{ }^{\circ} \mathrm{C}$ for $2 \mathrm{~h}$ followed by incubation with either $0.5 \mu \mathrm{g}$ MAb anti-Stx1 or $0.5 \mu \mathrm{g}$ MAb anti-Stx2. Antigen-antibody binding was detected by the addition of goat anti-mouse IgG-peroxidase conjugate $(1: 5,000)$ and $\mathrm{OPD}(0.5 \mathrm{mg} / \mathrm{mL})$ and $\mathrm{H}_{2} \mathrm{O}_{2}$ as enzyme substrates, and the peroxidase reaction was stopped by the addition of $1 \mathrm{~N} \mathrm{HCl}$. The 
absorbance was measured at $492 \mathrm{~nm}$ in a Multiskan EX ELISA reader. MAb reactivity to Stx expressed by STEC isolates was arbitrarily defined as low (1-30 ng), medium (31-60 ng) and high (61-100 ng) compared to the absorbance obtained with the reactivity of $100 \mathrm{ng}$ of purified toxins, which we considered a high reactivity level.

\subsection{Vero Cell Toxin Assays}

Vero cells $\left(1 \times 10^{5}\right.$ cells $\left./ \mathrm{mL}\right)$ were grown in 96-well plates in Dulbecco's medium (DMEM) in the presence of $10 \%$ FBS for $24 \mathrm{~h}$ for Vero cell assay (VCA) and neutralization assays. Cells were also cultivated under the same conditions in 24-well plates containing $13 \mathrm{~cm}$ diameter coverslips for immunofluorescence assay.

\subsubsection{VCA}

Half-maximal cytotoxic doses $\left(\mathrm{CD}_{50}\right)$ of the toxins were determined by VCA. $\log _{10}$ dilutions from $0.001 \mathrm{pg}$ to $10 \mu \mathrm{g}$ of each toxin were incubated with Vero cells at $37{ }^{\circ} \mathrm{C}$, in a $5 \% \mathrm{CO}_{2}$ atmosphere for $72 \mathrm{~h}$. This activity was determined as described by Gentry and Dalrymple [41]. Cell viability was determined using a spectrophotometer after staining the cells with crystal violet, and the percentage of cytotoxicity was calculated using the formula: control $A_{595} \mathrm{~nm}$ minus sample $\mathrm{A}_{595} \mathrm{~nm}$, divided by control $\mathrm{A}_{595} \mathrm{~nm}$. Cell monolayer in presence of medium and without toxins was employed as control of cell viability. These assays were performed twice in duplicate.

\subsubsection{Monoclonal Antibody Neutralizing Assays}

Neutralizing ability of anti-Stx 1 or anti-Stx 2 monoclonal antibodies was determined by incubating each toxin at the $\mathrm{CD}_{50}$ with different MAb concentrations from $0.4 \mathrm{pg}$ to $100 \mu \mathrm{g}$ for anti-Stx 1 or $0.4 \mathrm{pg}$ to $500 \mu \mathrm{g}$ for anti-Stx2. Culture supernatants of STEC producing Stx1 and/or Stx2 were incubated at 1:10 dilution with $30 \mu \mathrm{g}$ anti-Stx 1 and $500 \mu \mathrm{g}$ anti-Stx 2 monoclonal antibodies at $37{ }^{\circ} \mathrm{C}$ for $2 \mathrm{~h}$. Stx1- and Stx2-specific rabbit antisera were employed as neutralizing activity controls [33,34]. After incubation, these mixtures were tested as described by Beutin et al. [42]. These assays were performed three times in duplicate.

\subsubsection{Immunofluorescence and Confocal Analysis}

The immunofluorescence assay was performed as described by Dorsey et al. [43]. Toxins and cells were incubated at $37{ }^{\circ} \mathrm{C}$ for $0,2,6$ and $24 \mathrm{~h}$ using $0.1 \mathrm{pg}$ Stx 1 or $640 \mathrm{pg}$ Stx2. After this period, cells were washed with DMEM containing $2 \%$ FBS and then fixed with $4 \% \rho$-formaldehyde for $16-18 \mathrm{~h}$ at $4{ }^{\circ} \mathrm{C}$. The cells were washed three times with PBS and $1 \%$ glycine in PBS was added to quench excess aldehyde groups. After blocking with PBS containing 1\% BSA and incubation with $100 \mu \mathrm{g}$ anti-Stx 1 or $200 \mu \mathrm{g}$ anti-Stx 2 diluted in blocking buffer at $37^{\circ} \mathrm{C}$ for $1 \mathrm{~h}$, the antigen-antibody reaction was detected by the addition of anti-mouse IgG-FITC (1:100). The reaction was visualized with a confocal laser-scanning microscope (LSM 510 META). The image was obtained and analyzed with a confocal microscope Zeiss LSM image browser, and the cut-off was defined as the control reaction of Vero cells with either MAb anti-Stx1 or anti-Stx2 plus anti-mouse IgG-FITC in the absence of toxin. 


\subsubsection{Statistical Analysis}

The differences between isolates with regard to cytotoxicity and their corresponding neutralization by the MAbs was analyzed by GraphPrism ${ }^{\circledR} 5.01$, using Student's $t$-test and two-away ANOVA. The differences were considered statistically significant when $p \leq 0.05$.

\section{Results}

\subsection{Interaction of Monoclonal Antibodies with Stx 1 and Stx2}

The detoxification process was employed to reduce Stx1 and Stx2 toxicity to less than 1\% for mouse immunization. The immunization protocols used for Stx1 or Stx2 in BALB/c mice generated high IgG antibody titers for both toxins. The mean optical density at $492 \mathrm{~nm}$ was 1.0 up to 3200 -fold serum dilution in mice immunized with the two toxins.

Secretory hybridomas of antibodies against Stx1 and Stx 2 were obtained and subcloned by limiting dilution. Anti-Stx1 and anti-Stx2 MAbs produced by the selected clones (3E2 and 2E11, respectively), were classified as IgG1 and showed reactivity with their respective toxins by immunoblotting: anti-Stx $1 \mathrm{MAb}$ bound to the B subunit (Figure 1A) with a dissociation constant of $2.5 \times 10^{-10} \mathrm{M}$ (Table 1), while anti-Stx2 MAb bound to the A subunit (Figure 1B) with a dissociation constant of $6.1 \times 10^{-10} \mathrm{M}$ (Table 1$)$.

Figure 1. Nitrocellulose membranes containing purified toxins Shiga toxins (Stx)1 and Stx2. Immunoblotting reaction was carried out using anti-Stx1 MAb (A) and anti-Stx2 $\mathrm{MAb}(\mathrm{B})$. Apparent molecular weights found showed that the MAbs recognized their corresponding toxin. Arrows indicate toxin subunits.

A

$\mathrm{kDa}$

38 -

31.

24 -

17 .

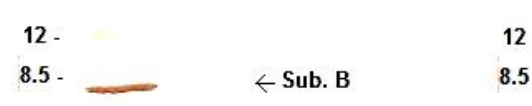

Stx1 Stx2
B

kDa

38 -

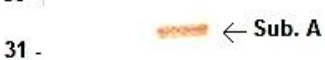

24 -

17 .

12 -

$8.5-$

Stx1 Stx2

Using $200 \mathrm{ng}$ MAbs to determine their ability to bind to the respective toxin, the detection limit was $6.2 \mathrm{ng}$ for anti-Stx 1 and $12.5 \mathrm{ng}$ for anti-Stx2, using an optical density of 0.1 as cut-off (Table 1). The equivalent cut-off was used for determining the reactivity and cross reactivity of MAbs and toxins. 
Anti-Stx1 (3E2) reacted with $0.1 \mu \mathrm{g}$ of Stx1 up to $19.5 \mathrm{ng}$ (Figure 2A), $2.5 \mu \mathrm{g}$ of anti-Stx1 MAb was necessary to detect the same amount of Stx2 (Figure 2B). For anti-Stx2 (2E11) the reactivity with the Stx2 was up to $18.7 \mathrm{pg}$ (Figure 2D) and $0.31 \mu \mathrm{g}$ was necessary to detect Stx1 (Figure 2C). These results show that cross reactivity occurrs only in the presence of higher MAb concentrations, which are excessive to detected theirs respective toxins.

The MAb stability parameters were quite different for both toxins. Anti-Stx2 MAb was stable up to $70{ }^{\circ} \mathrm{C}$, while anti-Stx 1 lost stability at $50{ }^{\circ} \mathrm{C}$ (Table 1). Moreover, a higher temperature and more time were necessary for anti-Stx 2 MAb to lose immunoreactivity compared with anti-Stx 1 MAb (Table 1).

Figure 2. Indirect ELISA using MAbs 3E2 and 2E11 and purified toxins Stx1 or Stx2. ELISA microtiter was coated with $0.1 \mu \mathrm{g}$ of Stx1 (A and B) and Stx2 (C and D). The reaction was carried out using different concentrations of anti-Stx1 MAb, 3E2 (A and C) or anti-Stx2 MAb 2E11 (B and D). The cut-off was defined as 0.1 OD. Cross reactivity occurred at high MAbs concentration.

A

B
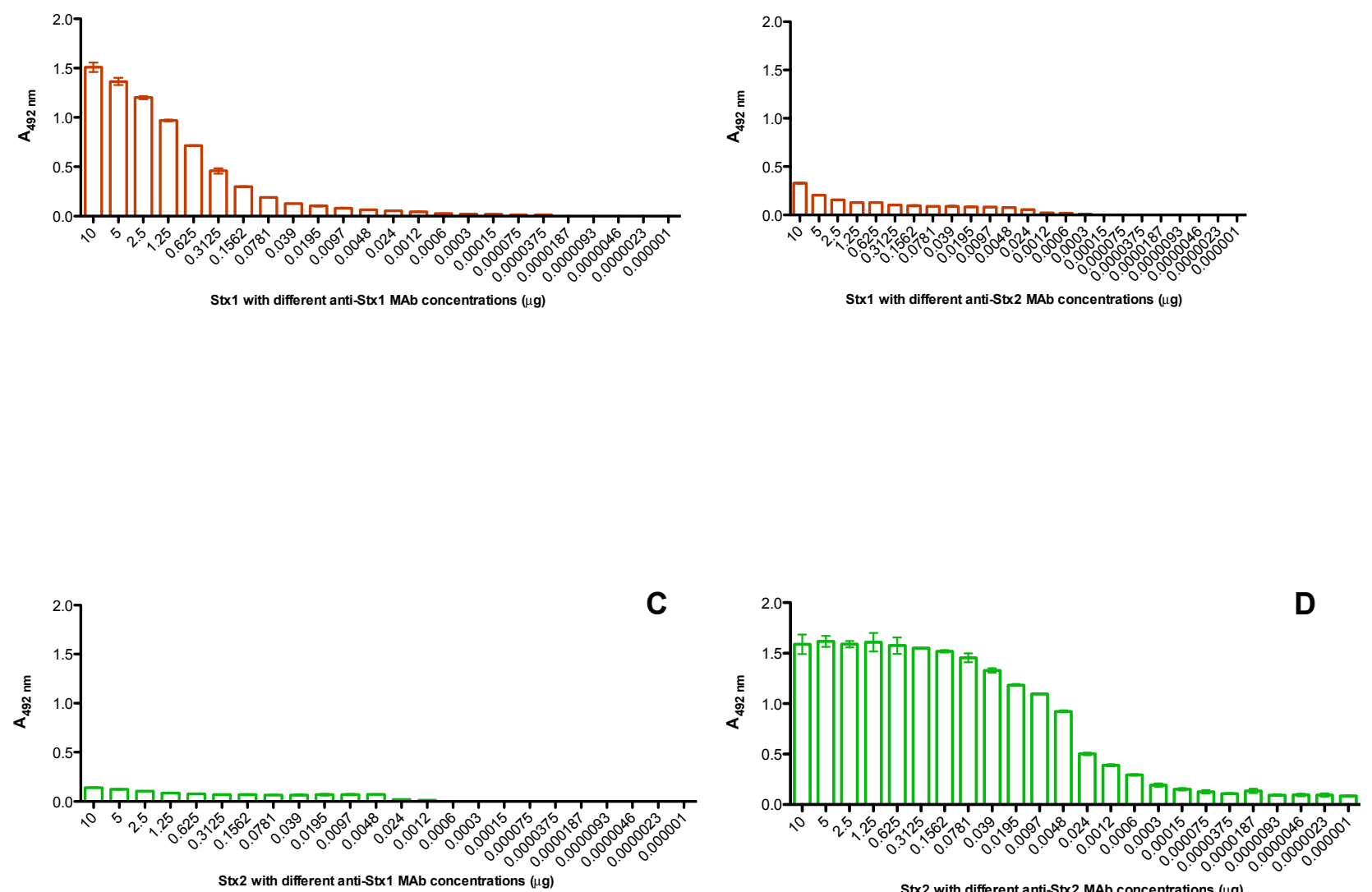

Stx2 with different anti-Stx2 MAb concentrations ( $\mu \mathrm{g}$ ) 
Table 1. Features of anti-Stx1 and anti-Stx2 MAbs.

\begin{tabular}{lcc}
\hline MAb characteristic & Anti-Stx1 & Anti-Stx2 \\
\hline Hybridomas & $3 \mathrm{E} 2$ & $2 \mathrm{E} 11$ \\
Dissociation constant $\left(K_{D}\right)$ & $2.5 \times 10^{-10} \mathrm{M}$ & $6.1 \times 10^{-10} \mathrm{M}$ \\
Detection limit $(200 \mathrm{ng})$ & $6.2 \mathrm{ng}$ & $12.5 \mathrm{ng}$ \\
Thermostability & $50^{\circ} \mathrm{C}$ & $70^{\circ} \mathrm{C}$ \\
Total loss of immunoreactivity $\left(80^{\circ} \mathrm{C}\right)$ & $1 \mathrm{~min}$ & $5 \mathrm{~min}$ \\
Partial loss of immunoreactivity & $60^{\circ} \mathrm{C}$ and $70^{\circ} \mathrm{C}$ & $80^{\circ} \mathrm{C}$ and $90^{\circ} \mathrm{C}$. \\
\hline
\end{tabular}

The kinetics of the toxins was analyzed by incubating the toxins at $0,2,6$ and $24 \mathrm{~h}$ with Vero cells. After fixation, these interactions were visualized after the MAb reaction (Figure 3). In the early periods ( 0 and $2 \mathrm{~h}$ ) each MAb recognized only their respective toxins, but after $6 \mathrm{~h}$ both MAbs were able to identify the presence of both toxins in Vero cells, shown by immunofluorescence. Using confocal microscopy, we observed that fluorescence emission with the homologous toxin was more intense. Presence of either Stx1 or Stx 2 was observed along the cell when anti-Stx1 was employed (Figure 3). The pattern of recognition by the anti-Stx2 MAbs with either Stx1 or Stx2 was limited to the cell border (Figure 3). Assay specificity was assured by interaction of monoclonal antibodies with Vero cells in the absence of toxin (Figure 3).

Figure 3. Immunofluorescence assay after Stx 1 or Stx 2 interaction with Vero cells for 0, 2, 6 and $24 \mathrm{~h}$. The reaction was carried out by incubating the cells with anti-Stx1 or anti-Stx2 MAbs. Cells labeled with FITC displayed an apple green fluorescence, showing that MAbs were able to recognize the toxins after cell interaction. Reactivity of anti-Stx1 or anti-Stx2 MAbs with cells and the anti-IgG mouse FITC in the absence of toxins was used as the negative control (C-), besides the differential interference contrast (DIC) of negative control. Reactivity was visualized with a confocal laser-scanning microscope (LSM 510 META).
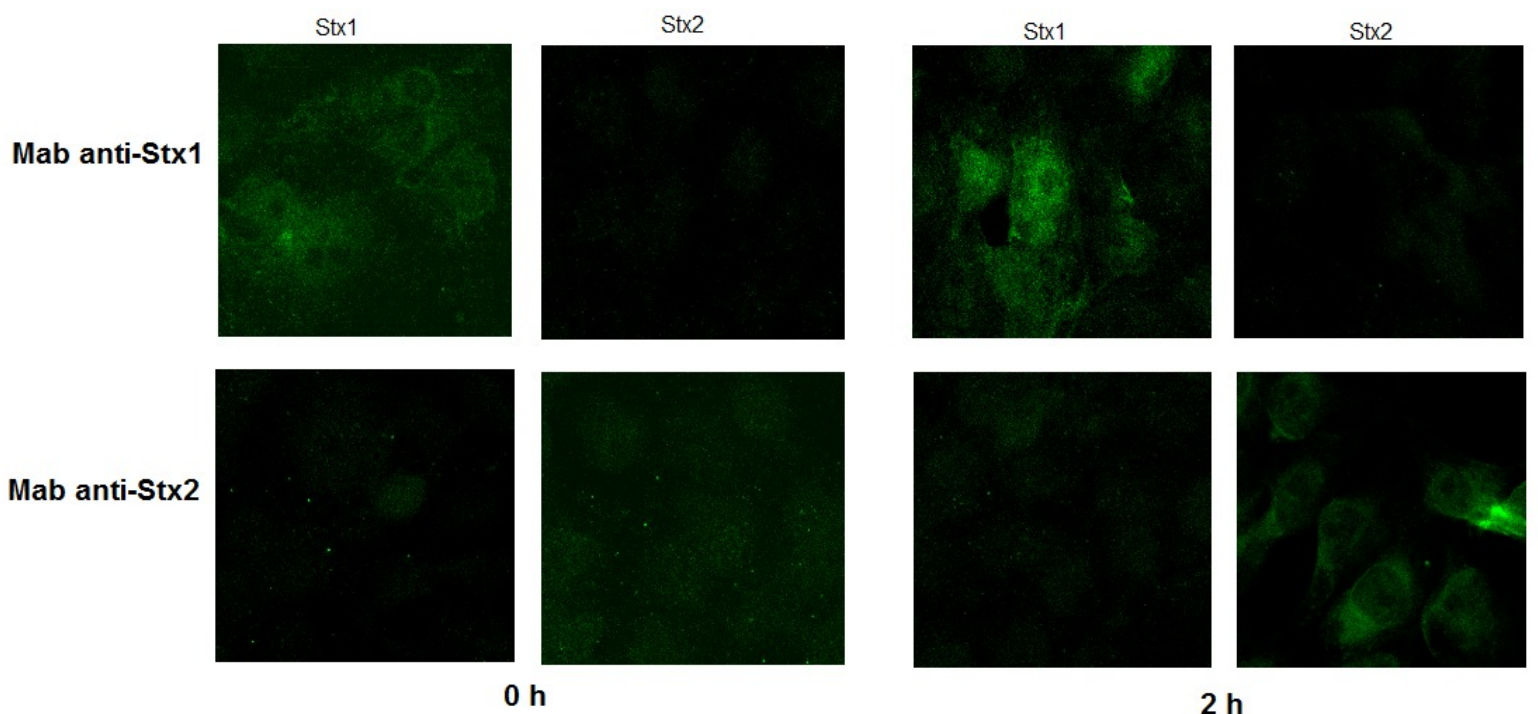
Figure 3. Cont.
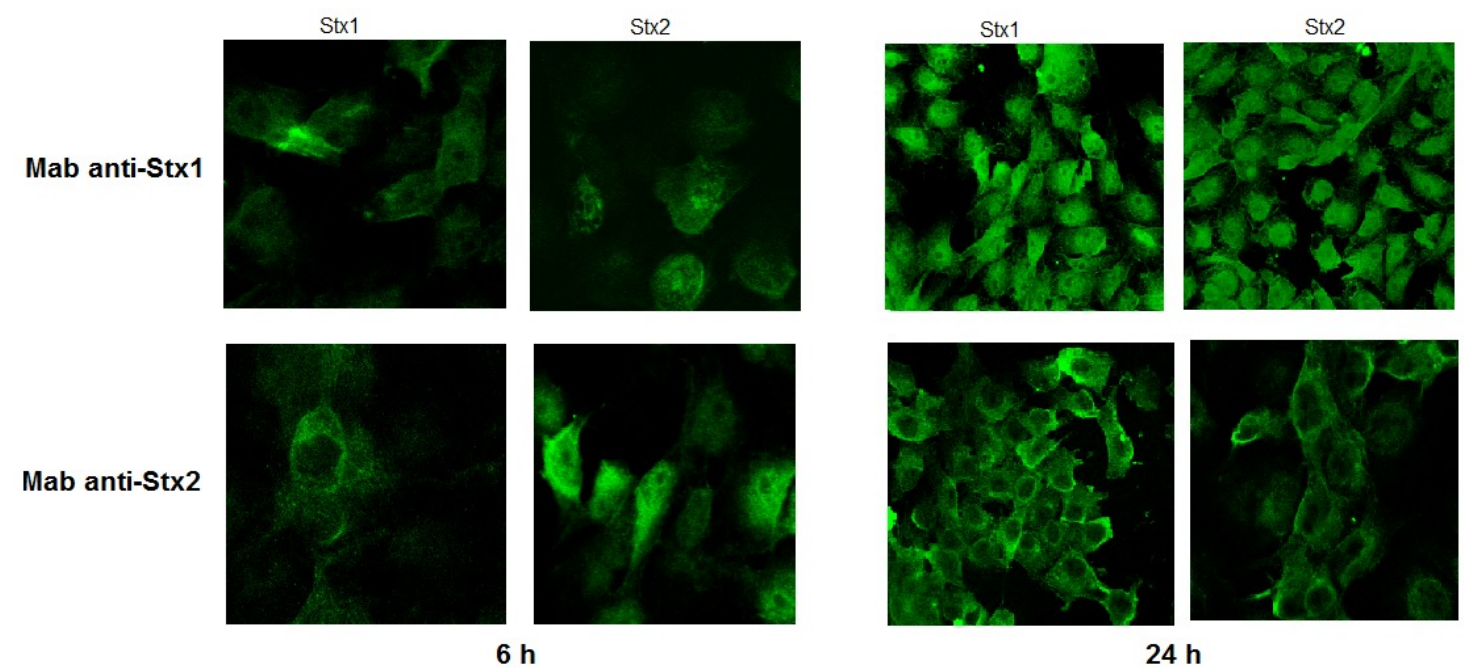

$24 \mathrm{~h}$

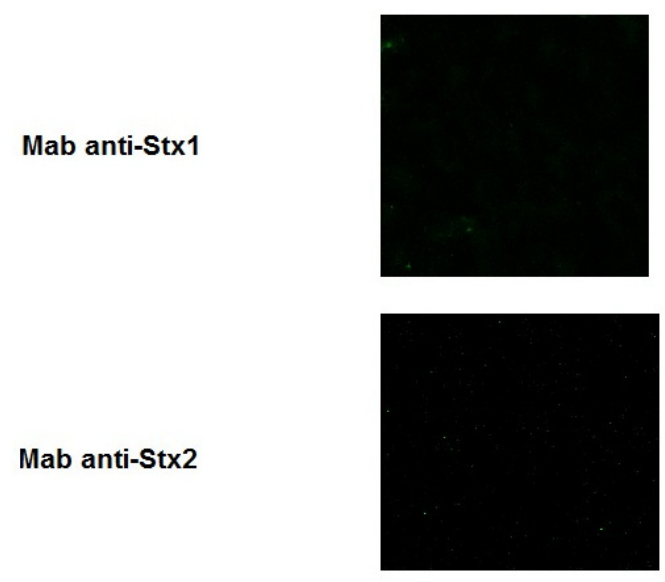

C-
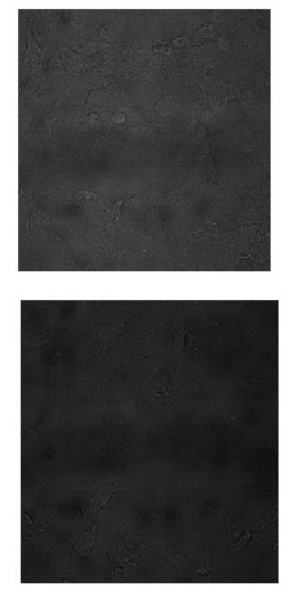

DIC

MAb reactivity with STEC isolates was determined by capture ELISA. Data from this experiment showed not only MAb reactivity but also allowed us to infer which toxins were produced by STEC isolates, thus anti-Stx 1 and anti-Stx2 MAbs detected the toxins expressed even at low levels (Table 2), demonstrating the diagnostic sensitivity of the MAbs. Furthermore, the reactivity of the MAbs matched the presence of the stx 1 and stx 2 genes, confirming their specificity. Just in one case (isolate 036, O75:H8), stx2 gene was amplified but the respective protein was not detected by anti-Stx 2 MAb. However, stx 1 gene was detected in the same isolate, and anti-Stx1 MAb recognized the respective toxin.

Table 2. Shiga toxin (Stx)-producing Escherichia coli characteristics.

\begin{tabular}{llccc}
\hline \multirow{2}{*}{ Strain number } & \multirow{2}{*}{ Serotype } & Gene presence & \multicolumn{2}{c}{ Reactivity to MAbs } \\
Anti-Stx1 & Anti-Stx2 \\
\hline 597 & OR:NM & stxl & $\mathrm{H}$ & - \\
1132 & ONT:H49 & stx2 & - & $\mathrm{H}$ \\
1189 & ONT:H49 & stx2 & - & $\mathrm{H}$ \\
3003 & O48:H7 & stxl/stx2 & $\mathrm{M}$ & $\mathrm{M}$ \\
4123 & O26:H11 & stx1 & $\mathrm{M}$ & - \\
\hline
\end{tabular}


Table 2. Cont.

\begin{tabular}{|c|c|c|c|c|}
\hline D360/4/1 & O26:H11 & stx 1 & $\mathrm{M}$ & - \\
\hline $1557-77$ & O26:H11 & stx 1 & $\mathrm{H}$ & - \\
\hline $\mathrm{H} 30$ & O26:H11 & stx 1 & M & - \\
\hline H19 & O26:H11 & stx 1 & $\mathrm{M}$ & - \\
\hline EPEC199 & O26:H11 & stx 1 & M & - \\
\hline 3529 & O26:H11 & stx 1 & M & - \\
\hline 82 & O157:H7 & stx 1 & $\mathrm{H}$ & - \\
\hline 46240 & $\mathrm{O} 157: \mathrm{H} 7$ & stx $1 / s t x 2$ & $\mathrm{M}$ & $\mathrm{H}$ \\
\hline $3104-88$ & $\mathrm{O} 157: \mathrm{H} 7$ & stx $1 /$ stx 2 & M & $\mathrm{H}$ \\
\hline $3077-88$ & $\mathrm{O} 157: \mathrm{H} 7$ & stx 1 & M & - \\
\hline C7-88 & $\mathrm{O} 157: \mathrm{H} 7$ & stx 1 & $\mathrm{~L}$ & - \\
\hline C1520-77 & $\mathrm{O} 157: \mathrm{H} 7$ & stx $1 /$ stx 2 & $\mathrm{H}$ & $\mathrm{H}$ \\
\hline 1 & O157:H7 & stx 2 & - & $\mathrm{H}$ \\
\hline 2 & O157:H7 & stx 2 & - & $\mathrm{H}$ \\
\hline 4 & O93:H19 & stx $1 / s t x 2$ & $\mathrm{H}$ & $\mathrm{L}$ \\
\hline 5 & O55:H19 & stx 1 & $\mathrm{~L}$ & - \\
\hline 9 & $\mathrm{O} 103: \mathrm{H} 2$ & stx $1 /$ stx 2 & $\mathrm{H}$ & $\mathrm{H}$ \\
\hline 11 & O118:H16 & stx 1 & M & - \\
\hline 16 & O26:H11 & stx 1 & $\mathrm{~L}$ & - \\
\hline 20 & O111:H8 & stx 1 & $\mathrm{~L}$ & - \\
\hline 23 & O111:H8 & stx 1 & $\mathrm{~L}$ & - \\
\hline 26 & O111:NM & stx 1 & M & - \\
\hline 27 & O111:NM & stx 1 & M & - \\
\hline 41 & ONT:NM & stx 2 & - & $\mathrm{M}$ \\
\hline 44 & O98:H4 & stx $1 /$ stx 2 & M & $\mathrm{H}$ \\
\hline 45 & O181:H4 & stx $1 /$ stx 2 & M & $\mathrm{H}$ \\
\hline 53 & O98:H17 & stx $1 / s t x 2$ & $\mathrm{~L}$ & $\mathrm{H}$ \\
\hline 55 & O98:H17 & stx $1 /$ stx 2 & M & $\mathrm{H}$ \\
\hline 59 & ONT:H16 & $s t x 2$ & - & $\mathrm{L}$ \\
\hline 66 & O105:H18 & stx $1 /$ stx 2 & $\mathrm{H}$ & $\mathrm{H}$ \\
\hline 79 & $\mathrm{O} 22: \mathrm{H} 16$ & $s t x 2$ & - & $\mathrm{H}$ \\
\hline 81 & ONT:H38 & stx $1 /$ stx 2 & $\mathrm{H}$ & $\mathrm{H}$ \\
\hline 82 & $\mathrm{O} 112: \mathrm{H} 21$ & stx 2 & - & $\mathrm{H}$ \\
\hline 96 & O93:H19 & stx 2 & - & M \\
\hline $\mathrm{O} 1$ & ONT:H8 & stx 1 & $\mathrm{~L}$ & - \\
\hline O17 & $\mathrm{O} 112: \mathrm{H} 2$ & stx 1 & $\mathrm{~L}$ & - \\
\hline $\mathrm{O} 3$ & O172:NM & stx 2 & - & $\mathrm{H}$ \\
\hline $\mathrm{O} 22$ & ONT:H16 & stx 2 & - & $\mathrm{L}$ \\
\hline O36 & O75:H8 & stx $1 /$ stx 2 & M & - \\
\hline O55 & O146:H21 & stx $1 /$ stx 2 & $\mathrm{H}$ & $\mathrm{L}$ \\
\hline EDL 933 & $\mathrm{O} 157: \mathrm{H} 7$ & stx $1 /$ stx 2 & $\mathrm{H}$ & $\mathrm{H}$ \\
\hline
\end{tabular}

- - MAb reactivity lower than $0.99 \mathrm{ng}$; L- low level of MAb reactivity (1-30 ng); M-medium level of MAb reactivity (31-60 ng); H-high level of MAb reactivity (61-100 ng). Arbitrary classification based on the obtained absorbance with $100 \mathrm{ng}$ purified Stx1 or Stx2, which was considered to be a high level of reactivity by capture ELISA. 


\subsection{Neutralizing Ability of Monoclonal Antibodies}

The $\mathrm{CD}_{50}$ of each toxin was determined prior to neutralization assays using anti-Stx1 and anti-Stx2 MAbs. $\mathrm{CD}_{50}$ was defined as $10 \mathrm{ng}$ and $500 \mathrm{ng}$ for Stx1 and Stx2, respectively. Concentrations of anti-Stx1 MAb ranging from $1.28 \mathrm{ng}$ to $100 \mu \mathrm{g}$ neutralized between 30 and $80 \%$ of Stx 1 cytotoxic activity (Figure 4A). Anti-Stx1 MAb showed cross-reactivity (Figure 4B), i.e., it inhibited both Stx1 and Stx 2 activity to the same extent. On the other hand, $100 \mu \mathrm{g}$ or $200 \mu \mathrm{g}$ anti-Stx $2 \mathrm{MAb}$ were necessary to neutralize ca. $35 \%$ of Stx 2 activity, and $60 \%$ of neutralization was only achieved using $500 \mu \mathrm{g}$ MAb (Figure 4C). No apparent cell damage was observed in any MAb concentration.

Figure 4. $\mathrm{A}$ and $\mathrm{B}$ - anti-Stx1 MAb showed cross-reactivity and was able to inhibit between 70 and $80 \%$ of both toxins ((A) Stx1 and (B) Stx2). Higher concentrations of anti-Stx2 MAb (100 to $500 \mu \mathrm{g})$ were necessary to neutralize Stx2 activity (C), but not Stx1 (data not shown). Bars represent the mean and the standard errors of the percentage of duplicates of three independent experiments.

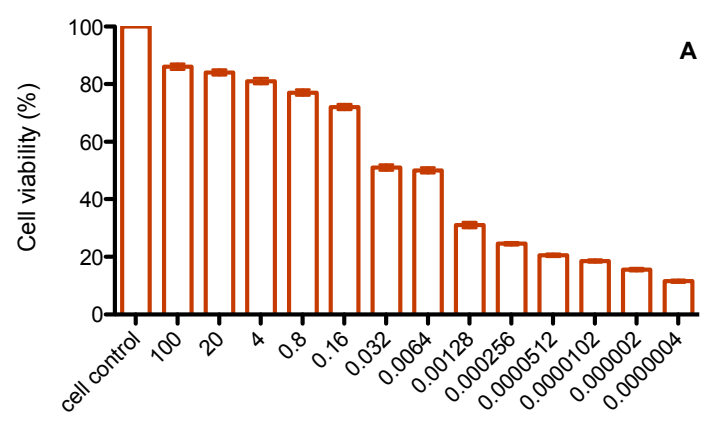

Stx1 with different anti-Stx1 MAb concentrations $(\mu \mathrm{g})$
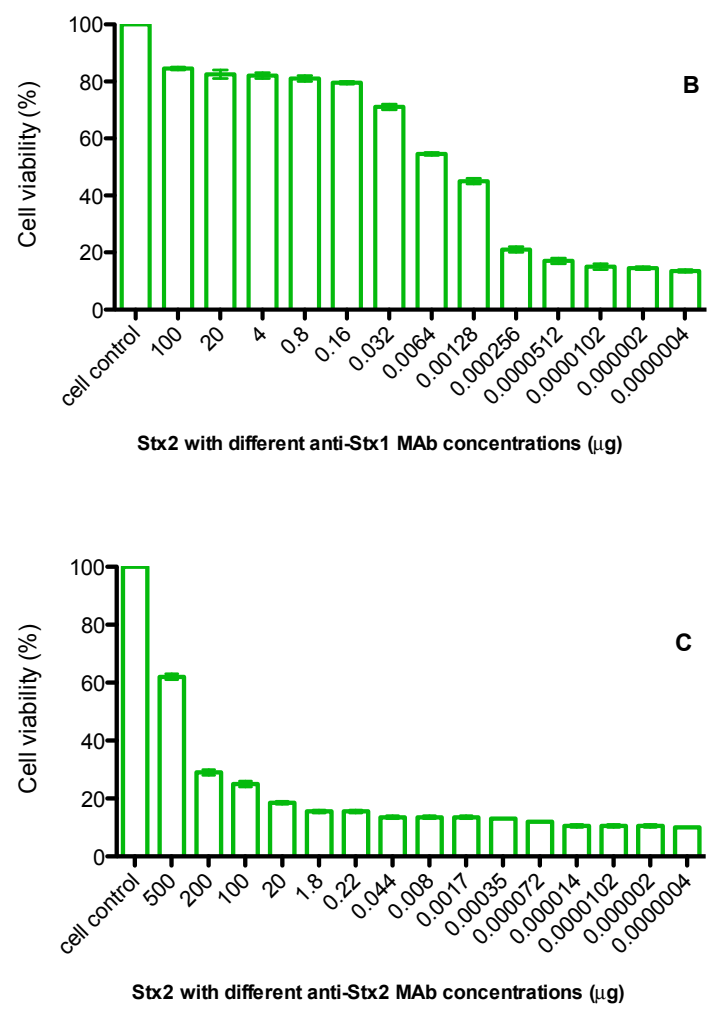
After determining the neutralization point for both MAbs, their ability to neutralize the cytotoxic activity of the STEC strains, belonging to several serotypes and showing either stx 1 , stx 2 or stx $1 /$ stx 2 genes, was investigated. We observed that Stx activity was neutralized (from 25 to $80 \%$ ) by the MAbs in all isolates (Figure 5). Besides, using both MAbs, we were able to neutralize Stx1 and Stx2 expressed by isolates. Cellular integrity was maintained at these MAb concentrations in the absence of toxins. Means and variances were significantly different $(p<0.0001)$ by Student's $t$-test and 2-way ANOVA, comparing the cytotoxicity and neutralization groups (Figure 5).

Figure 5. Vero cell cytotoxicity assay (VCA) and neutralization assays with culture supernatant of 46 shiga toxin-producing Escherichia coli (STEC) isolates producing Stx1 and/or Stx2 incubated with (blue) or without (red) anti-Stx1 and anti-Stx2 MAbs followed by cell incubation. Cytotoxicity and neutralization were determined after staining the cells with crystal violet and measuring absorbance at $595 \mathrm{~nm}$. Means and variances were significantly different $(p<0.0001)$ by Student's $t$-test and 2-way ANOVA comparing cytotoxicity and neutralization groups. Bars represent the OD means and standard errors median of duplicates of three independent experiments. A high OD value means high cell viability.

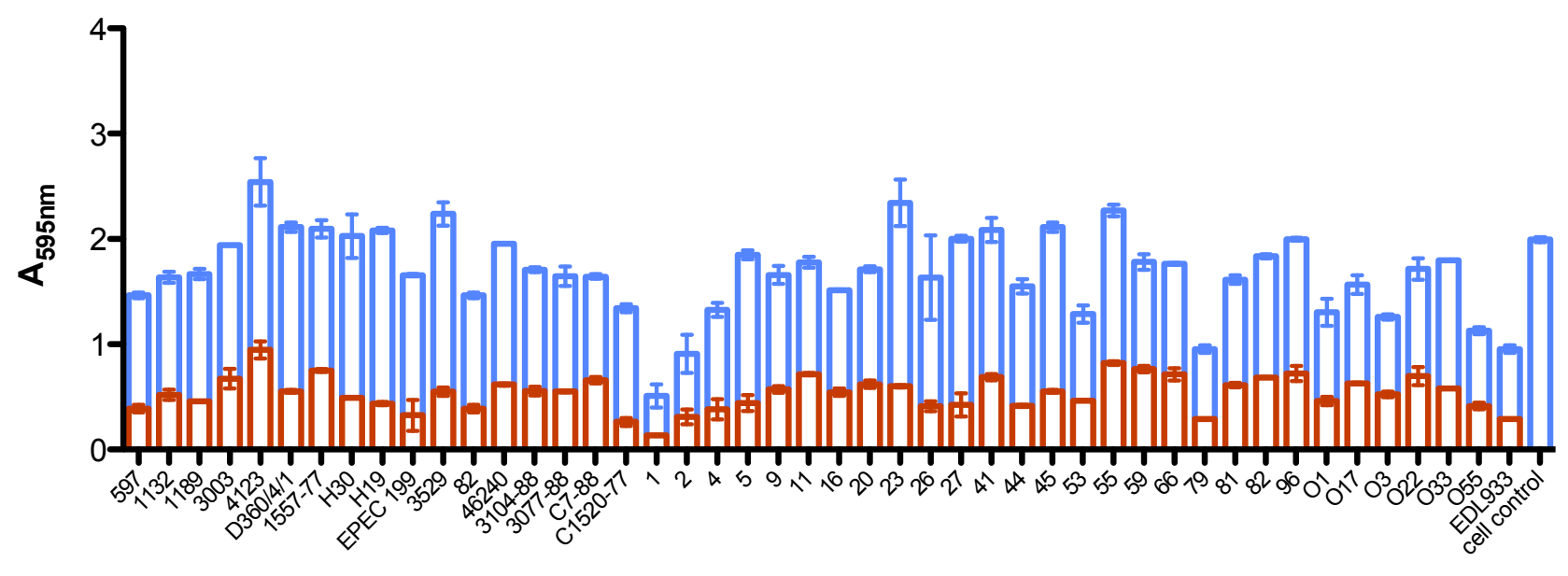

STEC isolates

\section{Discussion}

A number of anti-Stx MAbs showing different features have been described in the literature [19,23,24,30,35,44-49], including their use for diagnosis, but just for Stx1 and for O157:H7 recognition [49]. Thus, raising monoclonal antibodies takes a remarkable effort, and developing them as tools for diagnosis or therapy is a major struggle.

Anti-Stx1 and anti-Stx2 MAbs obtained in the present study were produced against toxins converted to toxoids by either formaldehyde or glutaraldehyde treatment [35,36]. The 3E2 clone was obtained in the first fusion after Stx1 treatment by glutaraldehyde and using the immunization and fusion protocols already described by our group either for the MAbs IgG2b anti-LT or IgG2b anti-intimin [50-52]. In contrast, the 2E11 clone was merely obtained after ten fusions, through different tested protocols either for toxoid conversion or route and schedule immunization. Among the 
six clones obtained, only 2E11 produced antibodies that were reactive to Stx-producing strains with high affinity and showed no reactivity with non-Stx-expressing strains (data not shown).

Anti-Stx1 and anti-Stx2 were classified as IgG1, as in case of MAbs already produced by other research groups as a consequence of the long schedule of mouse immunization with Stx toxoids [23,24,45]. Furthermore, these MAbs showed an efficient interaction with their respective toxin as indicated by their high dissociation constants and their ability to detect low levels of both purified toxins as well as low-producer isolates. In fact, among the described MAbs the affinity constant was cited in few studies. The studies by Tanikawa et al. [53] and Kimura et al. [26] showed the $K_{D}$ of $2.6 \times 10^{-10} \mathrm{M}$ for anti-Stx $1 \mathrm{MAb}$ and the $K_{D}$ of $2.3 \times 10^{-9} \mathrm{M}$ for anti-Stx2A MAb, which are similar to our described MAbs.

Another important characteristic was the stability of MAbs at high temperatures and the reactivity of anti-Stx1 or anti-Stx2 with their homologous toxin by indirect ELISA. 3E2 reacted with the B subunit of Stx1, while 2E11 recognized the A subunit of Stx2 by immunoblotting. This variation in reactivity is very common and has been shown by other groups with anti-Stx1 MAbs that either react with the A subunit [28] or the B subunit [24] or are conformational [30]. MAbs against Stx2 reacting with either the A or B subunit have also been described $[23,44,45,47]$. In the present study, both MAbs recognized only their specific denatured toxin by immunoblotting. Besides, the cross reactivity was only observed using high antibody concentrations by indirect ELISA. Surprisingly, when native protein was used by in vitro interaction assay, both MAbs showed cross reactivity after $6 \mathrm{~h}$ of toxin-Vero cells interaction, despite different recognition patterns.

An in vitro cytotoxicity assay was performed to evaluate the conditions by which the MAbs were able to neutralize the cytotoxic effects of Stx1 and/or Stx2. The neutralizing ability of the produced MAbs showed that anti-Stx1 MAb neutralized the binding of Stx1 and Stx2 to Vero cells. On the other hand, anti-Stx 2 neutralized only the homologous toxin, and a higher concentration of this MAb was necessary. The correlation between subunit reactivity and neutralizing ability is variable. For example, Smith et al. [30] characterized a conformational MAb that neutralizes the Stx2 B subunit. The opposite was observed by Sheoran et al. [47] since the two MAbs tested failed to neutralize Stx2c in vitro due to their stronger reactivity with the B subunit than with the A subunit of Stx 2 by immunoblotting.

The clinical options for treatment of STEC still remain limited to mainly supportive strategies despite researchers' efforts in understanding this pathogen. No MAb is currently approved for clinical use, but promising options for the future are under investigation, including urtoxazumab against Stx2, which is undergoing clinical trials and appears to be safe, making it a potential candidate for the prevention of HUS in pediatric patients [31]. Also, another human monoclonal antibody [27,28] protected mice against lethal challenges with Stx2 and Stx2 variants [47]. Preclinical evaluation in a piglet model of infection showed protection against Stx2-induced fatal neurological symptoms, even when the antibody was administered after the onset of diarrhea and oral STEC challenge [54].

Given that STEC can produce any combination of Stx1, Stx2, and/or variants [55], an ideal therapeutic formulation should include MAbs specific for all them, which could provide broad-spectrum protection against Stx1 and/or Stx2 [27,28,47]. Our results suggest that the manipulation by site-directed mutagenesis of the single chain fragment variable ( $\mathrm{ScFv}$ ) of MAbs should be interesting to improve their affinity and allow the large-scale production of recombinant antibodies with desirable sensitivity and specificity. This is currently under way in our laboratory. 
Moreover, the previously described IgG-enriched fraction of anti-Stx 1 or anti-Stx 2 from rabbit polyclonal antiserum [33,34] together with anti-Stx1 or anti-Stx2 MAbs, showed high sensitivity in detecting Stx even in low-producer isolates by capture ELISA. Therefore, both MAbs can be used as tools for the diagnosis of STEC in view of their described features. Since antibody neutralizing efficiency in vivo usually correlates with its ability to protect cells against Stx-mediated toxicity [56], the in vitro neutralizing abilities of the described MAbs against the Shiga toxins encourage future studies to investigate their protective efficacy.

\section{Acknowledgments}

This work was supported by Fundação de Amparo à Pesquisa do Estado de São Paulo (FAPESP) and Conselho Nacional de Desenvolvimento Científico e Tecnológico (CNPq) grants awarded to R.M.F.P and I.F. (fellowship). LBR, DEL and AC are recipients of a FAPESP fellowship. Albert Leyva helped with the English editing of the manuscript.

\section{Competing interests}

The authors declare that they have no competing interests.

\section{References}

1. Tzipori, S.; Wachsmuth, I.K.; Chapman, C.; Birden, R.; Brittingham, J.; Jackson, C.; Hogg, J. The pathogenesis of hemorrhagic colitis caused by Escherichia coli O157:H7 in gnotobiotic piglets. J. Infect. Dis. 1986, 154, 712-716.

2. Tzipori, S.; Karch, H.; Wachsmuth, K.I.; Robins-Browne, R.M.; O’Brien, A.D.; Lior, H.; Cohen, M.L.; Smithers, J.; Levine, M.M. Role of a 60-megadalton plasmid and Shiga-like toxins in the pathogenesis of infection caused by enterohemorrhagic Escherichia coli O157:H7 in gnotobiotic piglets. Infect. Immun. 1987, 55, 3117-3125.

3. Levine, M.M. Immunoprophylaxis of Shiga toxin-producing Escherichia coli infection and disease: strengths and weaknesses of various strategies. In Escherichia coli O157:H7 and other Shiga toxin-producing E. coli strains; Kaper, J.B., O’Brien, A.D., Eds.; ASM Press: Washington, D.C., USA, 1998; pp. 405-408.

4. Fraser, M.E.M.; Chernaia, M.M.; Kozlov, Y.V.; James, M.N. Crystal structure of the holotoxin from Shigella dysenteriae at 2.5 Å resolution. Nat. Struct. Biol. 1994, 1, 59-64.

5. Fraser, M.E.M.; Fujinaga, M.M.; Cherney, A.R.; Melton-Celsa, E.M.; Twiddy, A.D.; O’Brien, M.N.; James, M.N. Structure of Shiga toxin type 2 (Stx2) from Escherichia coli O157:H7. J. Biol. Chem. 2004, 279, 27511-27517.

6. Ling, H.; Boodhoo, A.; Hazes, B.; Cummings, M.D.; Armstrong, G.D.; Brunton, J.L.; Read, R.J. Structure of the Shiga-like toxin I B-pentamer complexed with an analogue of its receptor Gb3. Biochemistry 1998, 37, 1777-1788.

7. Shimizu, H.R.A.; Field, S.W.; Homans, S.W.; Donohue-Rolfe, A. Solution structure of the complex between the B-subunit homopentamer of verotoxin VT-1 from Escherichia coli and the trisaccharide moiety of globotriaosylceramide. Biochemistry 1998, 37, 11078-11082. 
8. Thompson, G.S.; Shimizu, H.; Homans, S.W.; Donohue-Rolfe, A. Localization of the binding site for the oligosaccharide moiety of Gb3 on verotoxin 1 using NMR residual dipolar coupling measurements. Biochemistry 2000, 9, 13153-13156.

9. Hunt, J.M. Shiga toxin-producing Escherichia coli (STEC). Clin. Lab. Med. 2010, 30, 21-45.

10. Zoja, C.; Buelli, S.; Morigi, M. Shiga toxin-associated hemolytic uremic syndrome: pathophysiology of endothelial dysfunction. Pediatr. Nephrol. 2010, 25, 2231-40.

11. Bettelheim, K.A.; Beutin, L. Rapid laboratory identification and characterization of Verocytotoxigenic (Shiga toxin producing) Escherichia coli (VTEC/STEC). J. Appl. Microbiol. 2003, 95, 205-220.

12. Gerritzen, A.; Wittke, J.W.; Wolff, D. Rapid and sensitive detection of Shiga toxin-producing Escherichia coli directly from stool samples by real-time PCR in comparison to culture, enzyme immunoassay and Vero cell cytotoxicity assay. Clin. Lab. 2011, 57, 993-998.

13. CDC U.S. Centers for Disease Control and Prevention. Recommendations for Diagnosis of Shiga Toxin-Producing Escherichia coli Infections by Clinical Laboratories. MMWR 2009, 58, 1-12.

14. Kitov, I.P.; Paszkiewics, E.; Sadowska, J.M.; Deng, Z.; Ahmed, M.; Narain, R.; Griener, T.P.; Mulvey, G.L.; Armstrong, G.D.; Bundle, D.R. Impact of the nature and size of the polymeric backbone on the ability of heterobifunctional ligands to mediate shiga toxin and serum amyloid $\mathrm{P}$ component ternary complex formation. Toxins 2011, 3, 1065-1088.

15. Zhang, X.; McDaniel, A.D.; Wolf, L.E.; Keusch, G.T.; Waldor, M.K.; Acheson, D.W. Quinolone antibiotics induce Shiga toxin-encoding bacteriophages, toxin production, and death in mice. $J$. Infect. Dis. 2000, 181, 664-670.

16. Wong, C.S.; Jelacic, S.; Habeeb, R.L.; Watkins, S.L.; Tarr, P.I. The risk of the hemolytic-uraemic syndrome after antibiotic treatment of Escherichia coli O157:H7 infections. N. Engl. J. Med. 2000, 342, 1930-1936.

17. Tarr, P.I.; Gordon, C.A.; Chandler, W.L. Shiga-toxin-producing Escherichia coli and haemolytic uraemic syndrome. Lancet 2005, 365, 1073-1086.

18. Smith, K.E.; Wilker, P.R.; Reiter, P.L.; Hedican, E.B.; Bender, J.B.; Hedberg, C.W. Antibiotic treatment of Escherichia coli $\mathrm{O} 157$ infection and the risk of hemolytic uremic syndrome. Pediatr. Infect. Dis. J. 2012, 31, 37-41.

19. Smith, M.J.; Teel, L.D.; Carvalho, H.M.; Melton-Celsa, A.R.; O’Brien, A.D. Development of a hybrid Shiga holotoxoid vaccine to elicit heterologous protection against Shiga toxins types 1 and 2. Vaccine 2006, 24, 4122-4129.

20. Wen, S. X.; Teel, L.D.; Judge, N.A.; O’Brien, A.D. A plant-based oral vaccine to protect against systemic intoxication by Shiga toxin type 2. Proc. Natl. Acad. Sci. USA 2006, 103, 7082-7087.

21. Wen, S.X.; Teel, L.D.; Judge, N.A.; O’Brien, A.D. Genetic toxoids of Shiga toxin types 1 and 2 protect mice against homologous but not heterologous toxin challenge. Vaccine 2006, 24, $1142-1148$.

22. Edwards, A.C.; Melton-Celsa, A.R.; Arbuthnott, K.; Stinson, J.R.; Schmitt, C.K.; Wong, H.C.; O'Brien, A.D. Vero cell neutralization and mouse protective efficacy of humanized monoclonal antibodies against Escherichia coli toxins Stx1 and Stx2. In Escherichia coli O157:H7 and other Shiga toxin-producing E. coli strains; Kaper, J.B., O’Brien, A.D., Eds.; ASM Press: Washington, D.C., USA, 1998; pp. 388-392. 
23. Nakao, H.; Kiyokawa, N.; Fujimoto, J.; Yamasaki, S.; Takeda, T. Monoclonal antibody to Shiga toxin 2 which blocks receptor binding and neutralizes cytotoxicity. Infect. Immun. 1999, 67, 5717-5722.

24. Nakao, H.; Kataoka, C.; Kiyokawa, N.; Fujimoto, J.; Yamasaki, S.; Takeda, T. Monoclonal antibody to Shiga toxin 1, which blocks receptor binding and neutralizes cytotoxicity. Microbiol. Immunol. 2002, 46, 777-780.

25. Yamagami, S.; Motoki, M.; Kimura, T.; Izumi, H.; Takeda, T.; Katsuura, Y.; Matsumoto, Y. Efficacy of postinfection treatment with anti-Shiga toxin (Stx) 2 humanized monoclonal antibody TMA-15 in mice lethally challenged with Stx-producing Escherichia coli. J. Infect. Dis. 2001, 184, 738-742.

26. Kimura, T.; Co, M.S.; Vasquez, M.; Wei, S.; Xu, H.; Tani, S.; Sakai, Y.; Kawamura, T.; Matsumoto, Y.; Nakao, H.; Takeda, T. Development of humanized monoclonal antibody TMA-15 which neutralizes Shiga toxin 2. Hybrid Hybridomics 2002, 21, 161-168.

27. Mukherjee, J.; Chios, K.; Fishwild, D.; Hudson, D.; O’Donnell, S.; Rich, S.M.; Donohue-Rolfe, A.; Tzipori, S. Human Stx2-specific monoclonal antibodies prevent systemic complications of Escherichia coli O157:H7 infection. Infect. Immun. 2002, 70, 612-619.

28. Mukherjee, J.; Chios, K.; Fishwild, D.; Hudson, D.; O’Donnell, S.; Rich, S.M.; Donohue-Rolfe, A.; Tzipori, S. Production and characterization of protective human antibodies against Shiga toxin 1. Infect. Immun. 2002, 70, 5896-5899.

29. Dowling, T.C.; Chavaillaz, P.A.; Young, D.G.; Melton-Celsa, A.; O’Brien, A.; Thuning-Roberson, C.; Edelman, R.; Tacket, C.O. Phase 1 safety and pharmacokinetic study of chimeric murine-human monoclonal antibody c alpha Stx2 administered intravenously to healthy adult volunteers. Antimicrob. Agents Chemother. 2005, 49, 1808-1812.

30. Smith, M.J.; Carvalho, H.M.; Melton-Celsa, A.R.; O'Brien, A.D. The $13 \mathrm{C} 4$ antibody that neutralizes Shiga toxin type 1 (Stx1) recognizes three regions on the Stx1 B subunit and prevents Stx 1 from binding to its eukaryotic receptor globotriaosylceramide. Infect. Immun. 2006, 74, 6992-6998.

31. Lopez, E.L.; Contrini, M.M.; Glatstein, E.; Ayala, S.G.; Santoro, R.; Allende, D.; Ezcurra, G.; Teplitz, E.; Koyama, T.; Matsumoto, Y.; Sato, H.; Sakai, K.; Hoshide, S.; Komoriya, K.; Morita, T.; Harning, R.; Brookman, S. Safety and pharmacokinetics of urtoxazumab, a humanized monoclonal antibody, against Shiga-like toxin 2 in healthy adults and in pediatric patients infected with Shiga-like toxin-producing Escherichia coli. Antimicrob. Agents Chemother. 2010, 54, 239-243.

32. Vaz, T.M.; Irino, K.; Kato, M.A.; Dias, A.M.; Gomes, T.A.; Medeiros, M.L.; Rocha, M.M.; Guth, B.E. Virulence properties and characteristics of Shiga toxin-producing Escherichia coli in São Paulo, Brazil, from 1976 through 1999. J. Clin. Microbiol. 2004, 42, 903-905.

33. Rocha, L.B.; Piazza, R.M. Production of Shiga toxin by Shiga toxin-expressing Escherichia coli (STEC) in broth media: from divergence to definition. Lett. Appl. Microbiol. 2007, 45, 411-417.

34. Mendes-Ledesma, M.R.; Rocha, L.B.; Bueris, V.; Krause, G.; Beutin, L.; Franzolin, M.R.; Trabulsi, L.R.; Elias, W.P.; Piazza, R.M. Production and characterization of rabbit polyclonal sera against Shiga toxins Stx1 and Stx2 for detection of Shiga toxin-producing Escherichia coli. Microbiol. Immunol. 2008, 52, 484-491. 
35. Donohue-Rolfe, A.; Keusch, G.T.; Edson, C.; Thorley-Lawson, D.; Jacewicz, M. Pathogenesis of Shigella diarrhea. IX. Simplified high yield purification of Shigella toxin and characterization of subunit composition and function by the use of subunit-specific monoclonal and polyclonal antibodies. J. Exp. Med. 1984, 160, 1767-1781.

36. Brown, J.E.; Griffin, D.E.; Rothman, S.W.; Proctor, B.P. Purification and biological characterization of Shiga toxin from Shigella dysenteriae. Infect. Immun. 1982, 36, 996-1005.

37. Köhler, G.; Milstein, C. Continuous cultures of fused cells secreting antibody of predefined specificity. Biotechnology 1975, 24, 524-526.

38. Laemmli, U.K. Cleavage of structural proteins during the assembly of the head of bacteriophage T4. Nature 1970, 227, 680-685.

39. Studier, F.W. Analysis of bacteriophage T7 early RNAs and proteins on slab gels. J. Mol. Biol. 1973, 79, 237-248.

40. Friguet, B.; Chaffotte, A.F.; Djavadi-Ohaniance, L.; Goldberg, M.E. Measurements of the true affinity constant in solution of antigen-antibody complexes by enzyme-linked immunosorbent assay. J. Immunol. Methods 1985, 2, 305-319.

41. Gentry, M.K.; Dalrymple, J.M. Quantitative microtiter cytotoxicity assay for Shigella toxin. $J$. Clin. Microbiol. 1980, 12, 361-66.

42. Beutin, L.; Zimmermann, S.; Gleier, K. Evaluation of the VTEC-screen 'Seiken' test for detection of different types of Shiga toxin (verotoxin)-producing Escherichia coli (STEC) in human stool samples. Diagn. Microbiol. Infect. Dis. 2002, 42, 1-8.

43. Dorsey, F.C.; Fischer, J.F.; Fleckenstein, J.M. Directed delivery of heat-labile enterotoxin by enterotoxigenic Escherichia coli. Cell Microbiol. 2006, 8, 1516-1527.

44. Strockbine, N.A.; Marques, L.R.; Holmes, R.K.; O'Brien, A.D. Characterization of monoclonal antibodies against Shiga-like toxin from Escherichia coli. Infect. Immun. 1985, 50, 695-700.

45. Perera, L.P.; Marques, L.R.; O'Brien, A.D. Isolation and characterization of monoclonal antibodies to Shiga-like toxin II of enterohemorrhagic Escherichia coli and use of the monoclonal antibodies in a colony enzyme-linked immunosorbent assay. J. Clin. Microbiol. 1988, 26, 2127-2131.

46. Downes, F.P.; Barrett, T.J.; Green, J.H.; Aloisio, C.H.; Spika, J.S.; Strockbine, N.A.; Wachsmuth, I.K. Affinity purification and characterization of Shiga-like toxin II and production of toxin-specific monoclonal antibodies. Infect. Immun. 1988, 56, 1926-1933.

47. Sheoran, A.S.; Chapman, S.; Singh, P.; Donohue-Rolfe, A.; Tzipori, S. Stx2-specific human monoclonal antibodies protect mice against lethal infection with Escherichia coli expressing Stx2 variants. Infect. Immun. 2003, 71, 3125-3130.

48. Mohawk, K.L.; Melton-Celsa, A.R.; Robinson, C.M.; O'Brien, A.D. Neutralizing antibodies to Shiga toxin type 2 (Stx2) reduce colonization of mice by Stx2-expressing Escherichia coli O157:H7. Vaccine 2010, 28, 4777-4785.

49. Li, G.; Hong, J.; Huo, G.; Ren, X. Monoclonal antibodies against Stx1B subunit of Escherichia coli O157:H7 distinguish the bacterium form other bacteria. Lett. App. Microbiol. 2010, 51, 499-503. 
50. Menezes, C.A.; Gonçalves, D.S.; Amianti, J.; Fernandes, I.; Taddei, C.R.; Koga, P.C.M.; Trabulsi, L.R.; Martinez, M.B.; Piazza, R.M. Capture immunoassay for LT detection produced by enterotoxigenic Escherichia coli in bacterial isolates. Braz. J. Microbiol. 2003, 34, 11-13.

51. Menezes, C.A.; Imamura, S.Y.; Trabulsi, L.R.; Fernandes-Filho, A.; Martinez, M.B.; Guth, B.E.; Girão, D.M.; Piazza, R.M. Production, characterization, and application of antibodies against heat-labile type-I toxin for detection of enterotoxigenic Escherichia coli. Mem. Inst. Oswaldo Cruz 2006, 101, 875-880.

52. Menezes, M.A.; Rocha, L.B.; Koga, P.C.; Fernandes, I.; Nara, J.M.; Magalhães, C.A.; Abe, C.M.; Ayala, C.O.; Burgos, Y.K.; Elias, W.P.; Castro, A.F.; Piazza, R.M. Identification of enteropathogenic and enterohaemorrhagic Escherichia coli strains by immunoserological detection of intimin. J. Appl. Microbiol. 2010, 108, 878-887.

53. Tanikawa, T.; Ishikawa, T.; Maekawa, T.; Kuronane, K.; Imai, Y. Characterization of monoclonal immunoglobulin $\mathrm{A}$ and $\mathrm{G}$ against Shiga toxin binding subunits produced by intranasal immunization. Scand. J. Immunol. 2008, 68, 414-422.

54. Sheoran, A.S.; Chapman-Bonofiglio, S.; Harvey, B.R.; Mukherjee, J.; Georgiou, G.; Donohue-Rolfe, A.; Tzipori, S. Human antibody against Shiga toxin 2 administered to piglets after the onset of diarrhea due to Escherichia coli $\mathrm{O} 157: \mathrm{H} 7$ prevents fatal systemic complications. Infect. Immun. 2005, 73, 4607-4613.

55. Friedrich, A.W.; Bielaszewska, M.; Zhang, W.L.; Pulz, M.; Kuczius, T.; Ammon, A.; Karch, H. Escherichia coli harboring Shiga toxin 2 gene variants: frequency and association with clinical symptoms. J. Infect. Dis. 2002, 185, 74-84.

56. Jeong, K.I.; Chapman-Bonofiglio, S.; Singh, P.; Lee, J.; Tzipori, S.; Sheoran, A.S. In vitro and in vivo protective efficacies of antibodies that neutralize the RNA N-glycosidase activity of Shiga toxin 2. BMC Immunol. 2010, 24, 11-16.

(C) 2012 by the authors; licensee MDPI, Basel, Switzerland. This article is an open access article distributed under the terms and conditions of the Creative Commons Attribution license (http://creativecommons.org/licenses/by/3.0/). 